\title{
Profiling the circulating mRNA transcriptome in human liver disease
}

\author{
Aejaz Sayeed ${ }^{1}$, Brielle E. Dalvano ${ }^{1}$, David E. Kaplan ${ }^{2,3}$, Usha Viswanathan ${ }^{1}$, John $^{2}$ \\ Kulp ${ }^{1}$, Alhaji H. Janneh ${ }^{1,4}$, Lu-Yu Hwang ${ }^{5}$, Adam Ertel ${ }^{6}$, Cataldo Doria7 and Timothy \\ Block ${ }^{1}$ \\ ${ }^{1}$ Baruch S. Blumberg Institute, Doylestown, PA, USA \\ ${ }^{2}$ University of Pennsylvania Perelman School of Medicine, Philadelphia, PA, USA \\ ${ }^{3}$ The Corporal Michael J. Crescenz Veterans Administration Hospital, Philadelphia, PA, USA \\ ${ }^{4}$ Current address: Department of Biochemistry and Molecular Biology, Medical University of South Carolina, Charleston, SC, USA \\ ${ }^{5}$ Department of Epidemiology, Human Genetics and Environment Science Center for Infectious Diseases School of Public \\ Health, the University of Texas HSC, Houston, TX, USA \\ ${ }^{6}$ Department of Cancer Biology, Sidney Kimmel Cancer Center, Cancer Genomics Core Facility, Thomas Jefferson University, \\ Philadelphia, PA, USA \\ ${ }^{7}$ Capital Health Cancer Center, One Capital Way, Pennington, NJ, USA \\ Correspondence to: Aejaz Sayeed, email: Aejaz.sayeed@bblumberg.org \\ Keywords: hepatocellular carcinoma; circulating transcripts; biomarkers; liver cirrhosis; extracellular vesicles \\ Received: February 28, $2020 \quad$ Accepted: May 16, $2020 \quad$ Published: June 09, 2020
}

Copyright: Sayeed et al. This is an open-access article distributed under the terms of the Creative Commons Attribution License 3.0 (CC BY 3.0), which permits unrestricted use, distribution, and reproduction in any medium, provided the original author and source are credited.

\section{ABSTRACT}

The human circulation contains cell-free DNA and non-coding microRNA (miRNA). Less is known about the presence of messenger RNA (mRNA). This report profiles the human circulating mRNA transcriptome in people with liver cirrhosis (LC) and hepatocellular carcinoma (HCC) to determine whether mRNA analytes can be used as biomarkers of liver disease. Using RNAseq and RT-qPCR, we investigate circulating mRNA in plasma from HCC and LC patients and demonstrate detection of transcripts representing more than 19,000 different protein coding genes. Remarkably, the circulating mRNA expression levels were similar from person to person over the 21 individuals whose samples were analyzed by RNAseq. Liver derived circulating transcripts such as albumin (ALB), apolipoprotein (APO) A1, A2 \& H, serpin A1 \& E1, ferritin light chain (FTL) and fibrinogen like 1 (FGL1) were significantly upregulated in HCC patient samples. Higher levels of some of these liver-specific transcripts in the plasma of HCC patients were confirmed by RT-qPCR in another cohort of 20 individuals. Several less abundant circulating transcripts associated with cancer were detected in most HCC samples, but not in healthy subjects. Liver specificity of circulating transcripts was confirmed by investigating their expression in HCC tumor and liver cancer cell lines. Liver specific mRNA sequences in the plasma were predominantly present outside circulating extracellular vesicles.

Conclusions: The circulating "mRNA" transcriptome is remarkably consistent in diversity and expression from person to person. Detection of transcripts corresponding to disease selective polypeptides suggests the possibility that circulating mRNA can work as a biomarker analyte for cancer detection.

\section{INTRODUCTION}

We are interested in using mRNA in the blood as a source of biomarkers of liver disease. Circulating noncoding RNA, such as microRNA (miRNA), is routinely detected in the blood [1-3]. However, detection and understanding of circulating mRNA sequences is in a much earlier research phase. Several laboratories have demonstrated the existence of circulating mRNA in healthy subjects and those with a disease diagnosis [3-13]. For 
example, circulating hTERT mRNA levels have been reported to correlate with a diagnosis of hepatocellular carcinoma (HCC) $[14,15]$ and with tumor progression $[12$, $16,17]$. Albumin $(A L B)$ mRNA has also been detected in the circulation of advanced stage $\mathrm{HCC}$ patients and was reported to predict recurrence of HCC after transplantation [18, 19]. Additionally, during the preparation of this manuscript, circulating mRNA in cardiac disease patients was reported [3]. Although there are reports of specific mRNAs in select patient populations, a comprehensive study or "survey" specifically of circulating mRNA transcripts in liver disease patients has not been conducted. Circulating mRNA expression profiles, diversity, consistency, and heterogeneity across individuals is not clear. Also, the extent to which circulating mRNA is derived from "non-" blood tissue as opposed to blood or endothelial cells that line the blood is not clear. mRNA sequences in the blood, originating from non-blood cells, may be rare and/or may be representative of pathological events.

In this study, we analyzed total RNA isolated from adult human plasma. Briefly, RNAseq was performed on total RNA extracted from the plasma of 10 individuals with a diagnosis of HCC, 5 individuals with liver cirrhosis (LC) and no HCC, and 6 individuals with no evidence of liver disease. Seven of the $10 \mathrm{HCC}$ individuals also had underlying LC. Protein coding transcripts, or mRNA, were readily detected in all plasma samples and liver selective mRNA transcripts were particularly prominent in the plasma from HCC/LC patients. Some of the circulating mRNA transcripts corresponded to genes whose expression is known to be altered or mutated in HCC. The presence of a selected set of liver specific mRNA transcripts in the circulation was confirmed by RT-qPCR analysis of another 20 distinct plasma samples.

Although we are ultimately interested in identifying circulating mRNA markers of liver disease, this study primarily intended to determine if there is a circulating mRNA transcriptome, to identify the extent of its diversity and consistency from sample to sample, and to lay the groundwork for methods that can be used to identify transcripts that correlate with a disease diagnosis. These parameters of the circulating human liver mRNA transcriptome are discussed.

\section{RESULTS}

\section{Circulating RNA represents diverse transcripts from various tissues}

To evaluate the presence and diversity of mRNA transcripts in the human circulation, we performed RNAseq analysis on "total" cell-free RNA from the plasma of 10 individuals with $\mathrm{HCC}$ and LC, 5 with LC alone, and 6 "normal" healthy controls (NHC), bringing the total number of samples analyzed by RNAseq to 21 (Table 1). The HCC, $\mathrm{LC}$, and healthy individuals were similar in age. Although both genders and those with $\mathrm{HCC}$ and LC with and without chronic viral hepatitis were included in all liver disease categories, balance was not achieved with this opportunistic set. For each sequenced sample, more than 50 million reads were generated and transcript abundances are reported as transcripts per million (TPM). Our methods were designed to reduce ribosomal RNA (rRNA) and mitochondrial RNA (mtRNA) (Supporting Information). Results of the circulating transcripts were first organized by abundance (sorted by highest to lowest TPM in normal plasma) and then highly abundant transcripts from the top quadrant/upper quartile were investigated for the frequency of each RNA category. Among the $\sim 19,000$ distinct mRNA transcripts found in circulation, $65-75 \%$ of the coding transcripts represented the top quartile of all circulating RNA isolated using our method and this result was consistent across different clinical categories (Figure 1A). However, when analysis was based upon the entire transcriptome (instead of just the $75-100 \%$ most abundant transcripts), mRNA represented only $15 \%$ of the identified circulating RNA (Supplementary Figure 1).

It was of interest to track the original tissue source/s of circulating coding transcripts. Therefore, RNAseq data from each of the HCC $(n=10)$, LC $(n=5)$, and NHC $(n=6)$ plasma samples, as well as HCC $(n=2)$ and normal liver $(n=1)$ tissues were analyzed using TissueEnrich software (see Materials and Methods). The most abundant 1,200 mRNA transcripts were investigated. As shown in Figure 1B, circulating mRNA in NHC subjects, which included samples from equal numbers of both genders, contained coding transcripts from a variety of organs (liver, bone marrow, stomach, esophagus, prostate). The plasma from those with HCC and, not surprisingly, normal liver and liver tumor tissue was greatly enriched for transcripts identified as liver derived. Of note is that plasma from the 5 individuals with LC (but no HCC) was reduced in liver derived transcripts. This result is curious since plasma from people with HCC was not reduced in liver derived transcripts, yet most (7 of 10) of those with HCC were also diagnosed with LC. This finding could be an artefact of the small sample size and not be representative of larger populations or perhaps, most likely, the presence of HCC influences liver transcript levels in the circulation. The apparent reduction in amount of female organ transcripts in the HCC samples reflects the male gender imbalance in this sample set. Taken together, these data show that the liver is a major source of coding RNA (mRNA) present in the circulation. The presence of liver derived mRNA transcripts in the circulation of HCC patients provides strong evidence that non-blood mRNA transcripts can be readily detected in circulation.

\section{Expression profiles of circulating mRNA transcripts show minimal variability between individuals}

The consistency in levels (TPM) of any specific coding transcript between plasma samples was determined 
Table 1: Plasma samples used for RNAseq

\begin{tabular}{|c|c|c|c|c|c|c|c|}
\hline & $n$ & Age & Gender & HBV/HCV/NAFL/NASH & $\mathrm{LC}(n)$ & HCC stages (n) & HCC Stages (n) \\
\hline & & & $n=\mathbf{M} / \mathbf{F}$ & & & $\begin{array}{c}\text { AJCC I, II or } \\
\text { BCLC A, B }\end{array}$ & $\begin{array}{l}\text { AJCC III or } \\
\text { BCLC C, D }\end{array}$ \\
\hline $\mathrm{NHC}$ & 6 & 60.0 & $3 / 3$ & $0 / 0 / 0$ & $\mathrm{~N} / \mathrm{A}$ & N/A & $\mathrm{N} / \mathrm{A}$ \\
\hline $\mathrm{LC}$ & 5 & 59.6 & $5 / 0$ & $3 / 3 / 0$ & 5 & $\mathrm{~N} / \mathrm{A}$ & $\mathrm{N} / \mathrm{A}$ \\
\hline $\mathrm{HCC}$ & 10 & 62.7 & $7 / 3$ & $1 / 7 / 2$ & 8 & 6 & 4 \\
\hline
\end{tabular}

Early cancer (AJCC I, II; Barcelona A, B); Late (AJCC III; Barcelona C, D). N/A, Not Applicable. Plasma from 21 different individuals was used. $N=6$, from "normal healthy controls" (NHC), $n=5$ from those with a diagnosis of liver cirrhosis (LC) and $n=10$ from those with a diagnosis of hepatocellular carcinoma (HCC) and LC. For the HCC group: 7 of the 10 were also diagnosed with LC, 2 with NAFL; 6 BCLC A, B or AJCC I, II; 2 BCLC C, D or 2 with AJCC III A \& B. Ages and gender (Male $[\mathrm{M}]$, Female $[\mathrm{F}]$ ), as indicated. Individuals with chronic hepatitis B virus (HBV) or hepatitis $\mathrm{C}$ virus (HCV) or no evidence of viral hepatitis were included, as indicated. Diagnosis of HCC, LC and chronic viral hepatitis as in text.

by calculating the fold change of a transcript between the HCC and NHC samples and between the LC and NHC samples. Figure $2 \mathrm{~A}$ is a dot plot comparing $\log _{10}$ (fold change) between the HCC $(n=10)$ and $\mathrm{NHC}(n=6)$ patient plasma and shows that more than $94 \%$ of the identified genes' expression profiles varied less than 4 to 8 -fold between the cohorts. Figure 2B shows a volcano plot of the $-\log _{10}$ (fold change) of the variation between HCC $(n=10)$ and NHC $(n=6)$ versus the $p$-value of the same variation, and also suggests that the human mRNA transcriptome does not vary significantly from person to person (genes centered in the plot), at least for the individuals of differing age,

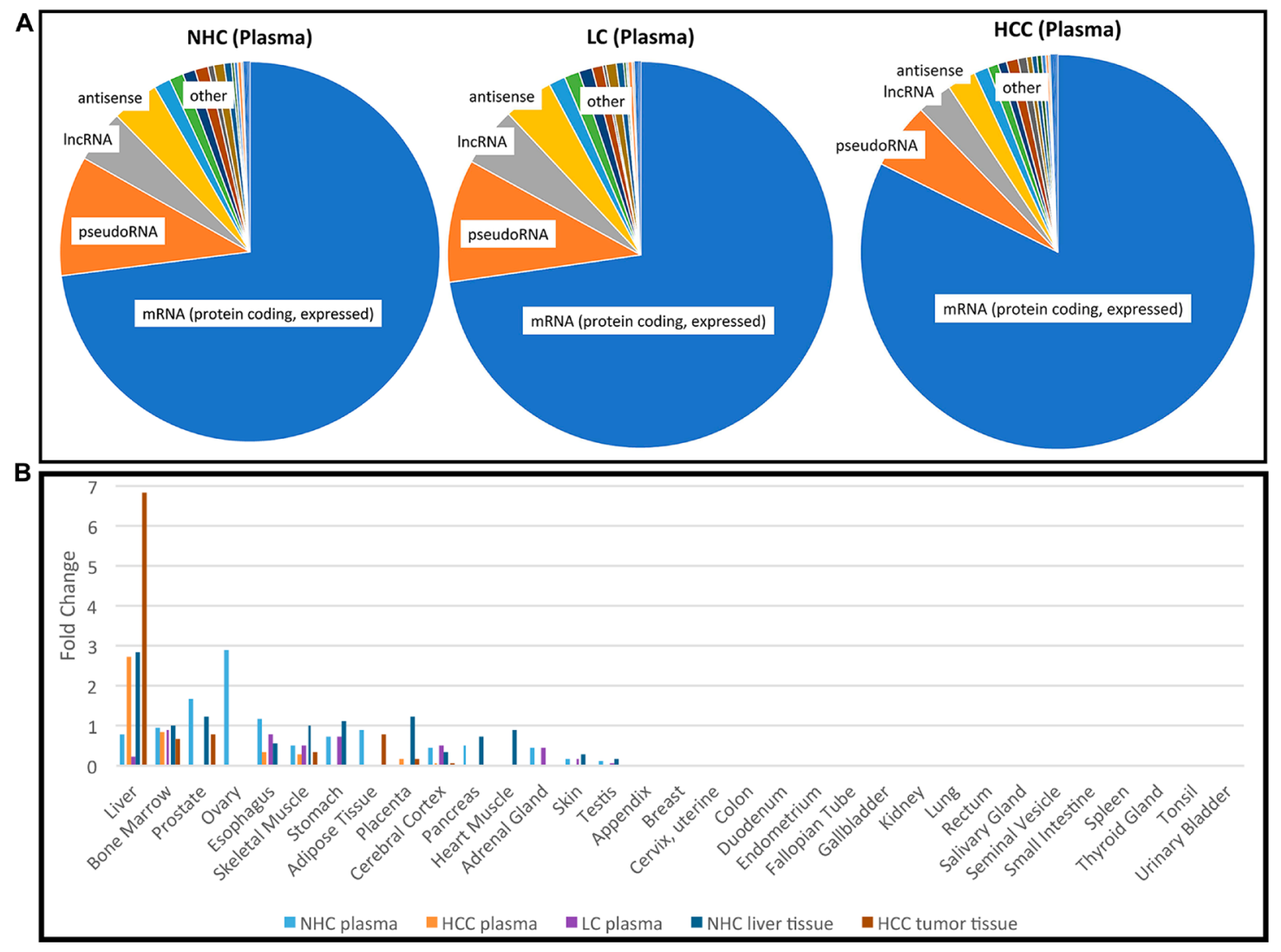

Figure 1: Profile of RNA present in the circulation. (A) Categories of the most abundant transcripts in the plasma from a cohort of HCC, LC, and NHC plasma samples. Pie charts represent the proportion of transcript types expressed in the top 25th percentile (75\% to $100 \%$ most abundant) of HCC $(n=10)$, LC $(n=5)$, and NHC $(n=6)$ plasma samples. Charts were generated by first identifying the top $25 \%$ abundant transcripts and then counting how often each category appeared. (B) Tissues of origin of mRNA transcripts detected in human plasma. Five different sample sets were compared: NHC plasma $(n=6)$, HCC plasma $(n=10)$, LC plasma $(n=5)$, normal liver tissue $(n=1)$, and HCC tumor tissue $(n=2)$. The top most 1,200 abundant protein coding genes in each sample category were analyzed using TissueEnrich software (see Materials and Methods) and compared with tissue specific genes from publicly available RNAseq datasets (Human Protein Atlas and GTEx using algorithm [49]). Tissue enrichment is expressed as fold change in each category. 
gender, and clinical condition analyzed here. Remarkably, the mRNA expression profile for each gene was generally consistent from person to person.

The consistency of expression profiles was also reflected in scatter plots with $\log _{2}$ (TPM) values for the 1,000 most abundant genes from each member of the NHC, HCC, and LC categories plotted against each gene's average $\log _{2}$ (TPM) (data not shown). Consistent expression profiles were evident when the average $\log _{2}$ (TPM) values of each disease category were plotted against each other (Figure 2C). Most striking from this analysis, which includes all 21 plasma samples, was the consistency in transcript expression, for any given gene, from sample to sample. It is clear from the scatter plots that the closer a value plotted to a diagonal line (slope $=1$ ), the closer it was to the average transcript amount, which indicated degrees of similarity or departure from the norm. It is noted that the highly abundant transcripts varied the least from patient to patient, the HCC patients had the greatest variability, and the variability was extreme for a subset of circulating transcripts.

These data collectively suggest that the circulating human transcriptome is relatively consistent from person to person, based on samples that range in age, gender, and liver disease category. That said, even though more than $94 \%$ of the gene transcripts between $\mathrm{HCC}$ vs. NHC and LC vs. NHC (data not shown) did not show more than 8 -fold variation, there were some differences in mRNA expression patterns between HCC and healthy subject samples that offer the possibility of identifying disease selective biomarker transcripts.

\section{Liver derived mRNA sequences are among the most abundant transcripts in circulation}

Although most of the circulating coding transcripts did not vary significantly in expression from person to person (Figure 2), some features of the expression analysis are notable. The detection of mRNA transcripts in the plasma that correspond to polypeptides derived from or enriched in the liver, such as $A L B, A P O A 1, A P O A 2$, APOB, APOH, SAA2, SERPINA1, SEPP1, ORM2, etc. (Figure $3 \mathrm{~A}$ ), and from other non-blood cells was striking and provides evidence that the circulation contains mRNA that originated in the liver and not from artefacts of the phlebotomy process. These liver derived transcripts were upregulated in the circulation of HCC patients as compared to those with LC. Figure 3A represents expression patterns $(\log 2(\mathrm{TPM}))$ of some abundant (base mean TPM between $200(A G T)$ and $9133(A L B))$ liver derived transcripts reflecting 3 to 7 -fold higher levels compared to those of LC patients $(p<0.01)$.

A subset of 50 circulating transcripts was identified for their differential expression between $\mathrm{HCC}$ and NHC groups and between LC and NHC groups. Briefly, the expression levels of the 50 transcripts, relative to the mean level of expression of each transcript, was determined and is illustrated using a heat map (Figure $3 \mathrm{~B})$. Hierarchical clustering of the expression profiles in 21 plasma samples shows that the HCC samples clustered together in the heat map (Figure 3B). HCC samples did appear to selectively have a common subset of elevated levels of mRNA transcripts. Additionally, some circulating transcripts selectively upregulated in HCC samples correspond to genes associated with malignancy and, in many cases, HCC (e. g., DUSP3 [20, 21], coagulation factor VII (F7) [22], FAS [23], ITGA9 [24, 25], NBPF12 [26], SNX16 [27], SDF2L1 [28-30], STRA13 [31], TRAP1 [32], SERPINE1 [33]). It is worth mentioning that the expression levels of 8 different transcripts corresponding to 5.8S rRNA were highly uniform in all samples analyzed by RNAseq, underscoring the accuracy and authenticity of RNAseq analysis and circulating expression profiles (data not shown). Despite using a method that aimed to minimize detection of mtRNA and rRNA, we observed that mitochondrial and ribosomal transcripts were the most highly abundant mRNA derived transcripts with uniform expression in the circulation of all individuals and could have been contributed by any organ or cells present in the blood (Supplementary Figure 2).

\section{Expression of circulating transcripts in $\mathrm{HCC}$ tumor and HCC cell lines}

Figure 1B above demonstrates that a substantial proportion of transcripts in the plasma of HCC patients are liver derived. Similarly, HCC tumor associated transcripts almost exclusively correspond to liver tissue. RNAseq data strongly suggest increased levels of a subset of liver specific transcripts in the circulation of HCC patients. Using the Human Protein Atlas (HPA) tissue gene expression dataset, which includes expression levels from 37 human tissues based on RNAseq, we identified a set of transcripts that are very selective for liver tissue, including ALB, HP, APOA2, APOH, SERPINA1, ORM1, and HPX. The genes' extreme liver specificity is demonstrated in Figure 4A. The levels of these transcripts were then experimentally determined in a set of liver cancer cell lines and a moderately differentiated human tumor tissue (HCC103T) using RT-qPCR and are illustrated in Figure 4B. Expression levels were normalized with levels of corresponding transcripts in immortalized nonmalignant PH5CH liver cells. Our data demonstrate significant overexpression $(p<0.01)$ of these transcripts in tumor tissue, as well as cancer cell lines (Figure 4B).

\section{Validation and detection of circulating mRNA by RT-qPCR}

To validate the presence of specific transcripts in patient circulation, we investigated a set of clinical samples that were studied earlier by RNAseq. RT- 
qPCR assays were carried out on circulating RNA from HCC patients $(n=4)$ and age and gender matched healthy controls $(n=4)$, and expression profiles of six liver derived transcripts were studied (Supplementary Figure 3). Data showed consistent expression profiles using RNAseq and RT-qPCR. Validation of circulating transcripts allowed for testing of specific mRNA transcripts in an additional independent set of samples from 20 individuals (10 with a diagnosis of $\mathrm{HCC}$ and 10 age and gender matched healthy subjects). In these 20 samples, the prevalence of 4 circulating liver specific transcripts, FTL, APOA2, SERPINA1, and ALB, was examined by RT-qPCR using exon specific primers (Supplementary Table 1). Figure 5A shows the results as average cycle threshold $(\mathrm{Ct})$ values in samples from the HCC patients and NHCs. Ct values reflect the number of PCR cycles required for the fluorescent signal from the amplified product to cross a threshold or background.
Primers specific for exons generated detectable products relatively consistent in amount from patient to patient. However, consistent with RNAseq data from the previous cohort, the transcripts tested were generally significantly upregulated in HCC samples as compared to the healthy subjects. Relative expression in HCC patients was calculated by normalizing with the $\mathrm{Ct}$ values of an internal reference control and also those of age and gender matched NHCs (Figure 5B). Figure 5B represents the same data as relative expression of $A P O A 2, A L B$, $F T L$, and SERPINA1 transcripts in each HCC patient sample in comparison to the average amount present in the NHCs $(n=10)$. Again, although the number of patient and healthy subject samples analyzed are too small to draw conclusions, the trends of elevated levels of these transcripts in HCC samples relative to healthy subjects observed with the sample sets used in RNAseq does seem to be sustained. Indeed, some HCC samples

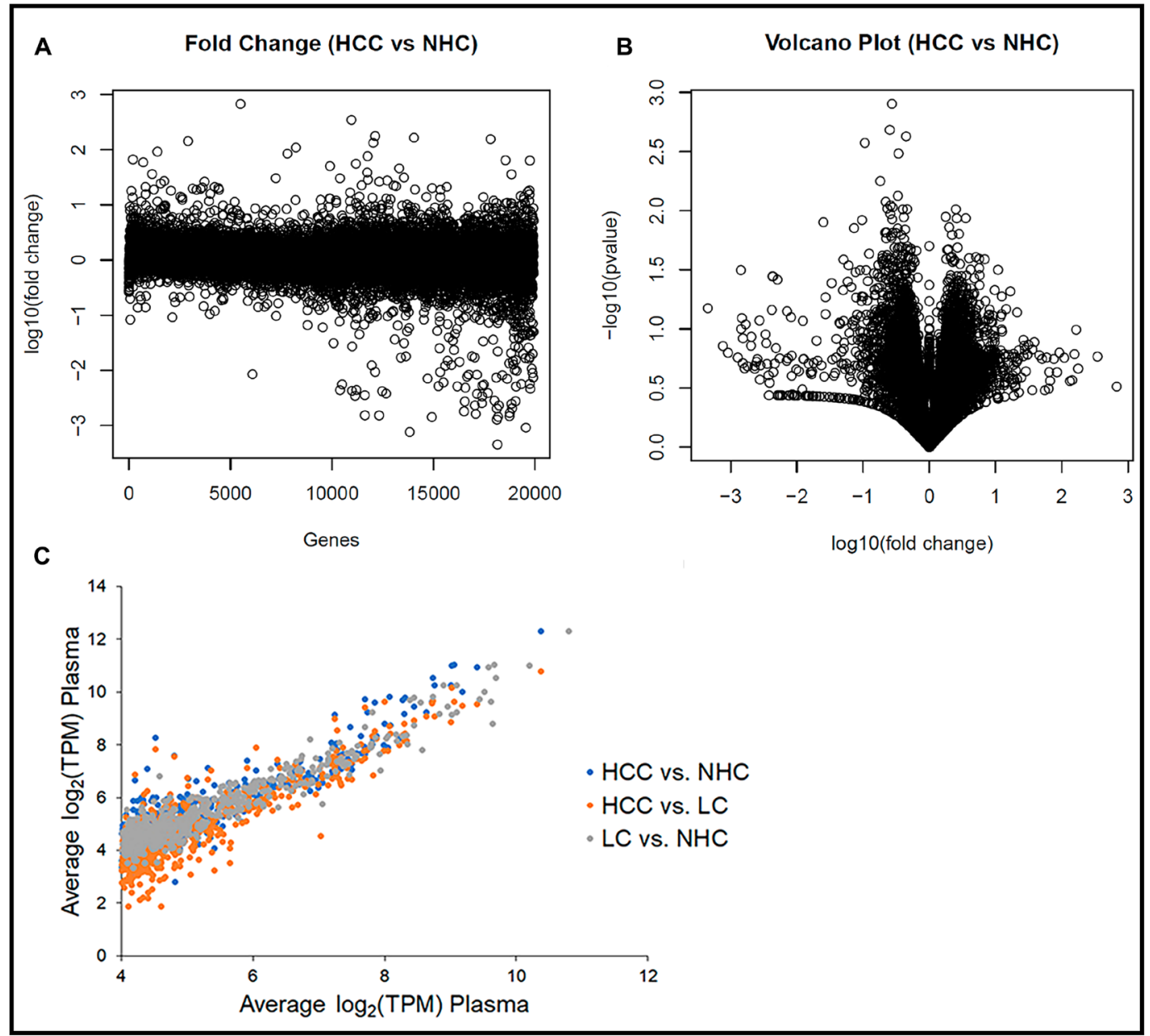

Figure 2: Human circulating transcriptome is essentially similar from person to person. (A) Transcript abundance (TPM) corresponding to each of $\sim 19,000$ coding regions in each sample as a function of fold difference from the mean of all samples. Plot of $\log _{10}$ (fold change) of the variation between HCC $(n=10)$ and NHC $(n=6)$ for each gene. (B) Volcano plot of the $-\log _{10}$ (fold change) of the variation between $\mathrm{HCC}(n=10)$ and $\mathrm{NHC}(n=6)$ vs. the $p$-value of the same variation. Genes toward the center of plot do not show significant variation, while those that are spread out show significant differences in terms of TPM. (C) The 1,000 most abundant circulating transcripts corresponding to protein coding genes graphed for each sample subset. Comparison of average gene expression (log 2 (TPM)) of the top 1,000 transcripts between HCC vs. NHC, HCC vs. LC, and LC vs. NHC categories. 

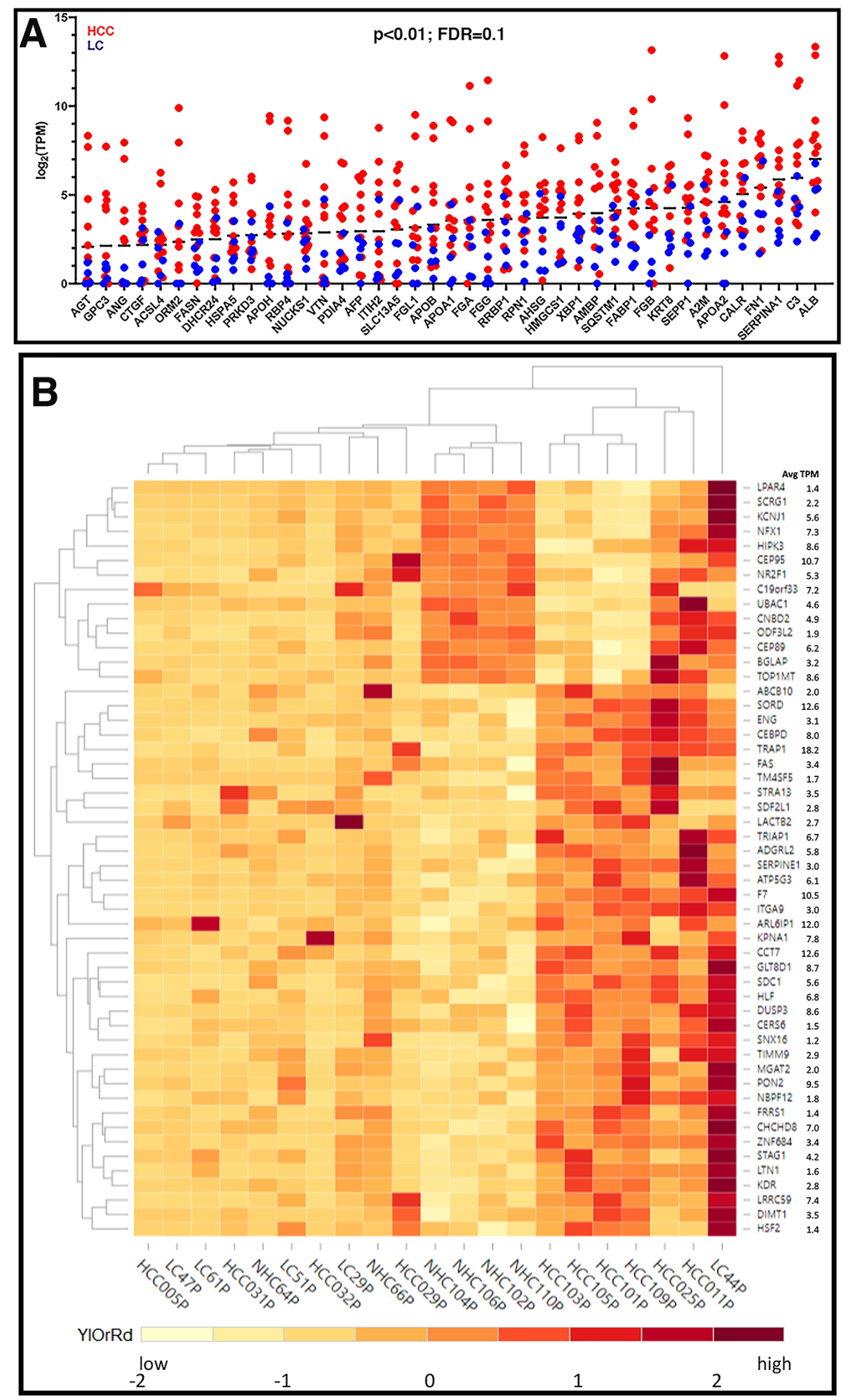

Figure 3: Expression profiles of unique circulating transcripts in liver disease. (A) Expression profiles (log2 (TPM)) of some abundant liver derived circulating transcripts with 3 to 7 -fold higher expression in HCC samples compared to LC samples $(p<0.01)$. (B) Hierarchical clustering of differentially expressed genes. Differentially expressed transcripts were identified by sorting the normalized TPMs around the mean (zero) such that the scaled TPM values for HCC vs. NHC and LC vs. NHC are opposite in signs (negative, low expression and positive, high expression) and the difference between group averages was at least ( \pm 1.5 ). The TPM values were scaled for each gene with the formula $(\mathrm{x}-\mu) / \sigma$, where $\mathrm{x}$ is variable data point, $\mu$ and $\sigma$ are the average and standard deviation for a gene, respectively, with color scheme YlOrRd (yellow, orange, red). 
had 9 to 20 -fold elevations in liver specific transcripts compared to LC samples.

\section{Liver derived circulating transcripts predominantly map to genomic exons and represent mature mRNA}

If the RNA sequences detected in the circulation were derived from mRNA, the transcripts should align with genic exons and lack intronic sequences as introns are not present in most mature mRNA. We analyzed the read piles for 6 liver derived transcripts from at least 10 individuals (5 HCC, $5 \mathrm{NHC}$ ) and found substantial representation of exons in sequencing reads. As an example, Figure 6 shows read pile profiles of three circulating mRNA transcripts (APOA2, FTL, and SERPINA1) in 8 distinct plasma samples. The data show that the sequencing reads of circulating transcripts predominantly correspond to exonic regions and that certain specific regions within exons are detected at a higher sequencing depth than other regions within a given transcript. To confirm the selective detection of exons in liver derived transcripts, nested semiquantitative PCR was performed on total, cell-free, DNase-treated RNA isolated from patient samples. Primers for $A P O A 2$ that amplify either intronic or exonic sequences (that span the intron) were used. Our data show the detection of exon specific products alone without any intron specific or intron containing PCR products (Figure 7A). Further, detection of APOA2 and FTL transcripts in patient plasma samples was also validated by nested PCR and LICOR 800 probe based Southern blotting (Figure 7B, Supplementary Table 1). The sensitivity of amplicon product detection increased when mRNA was either amplified using nested PCR or hybridized to gene specific probes via Southern blot

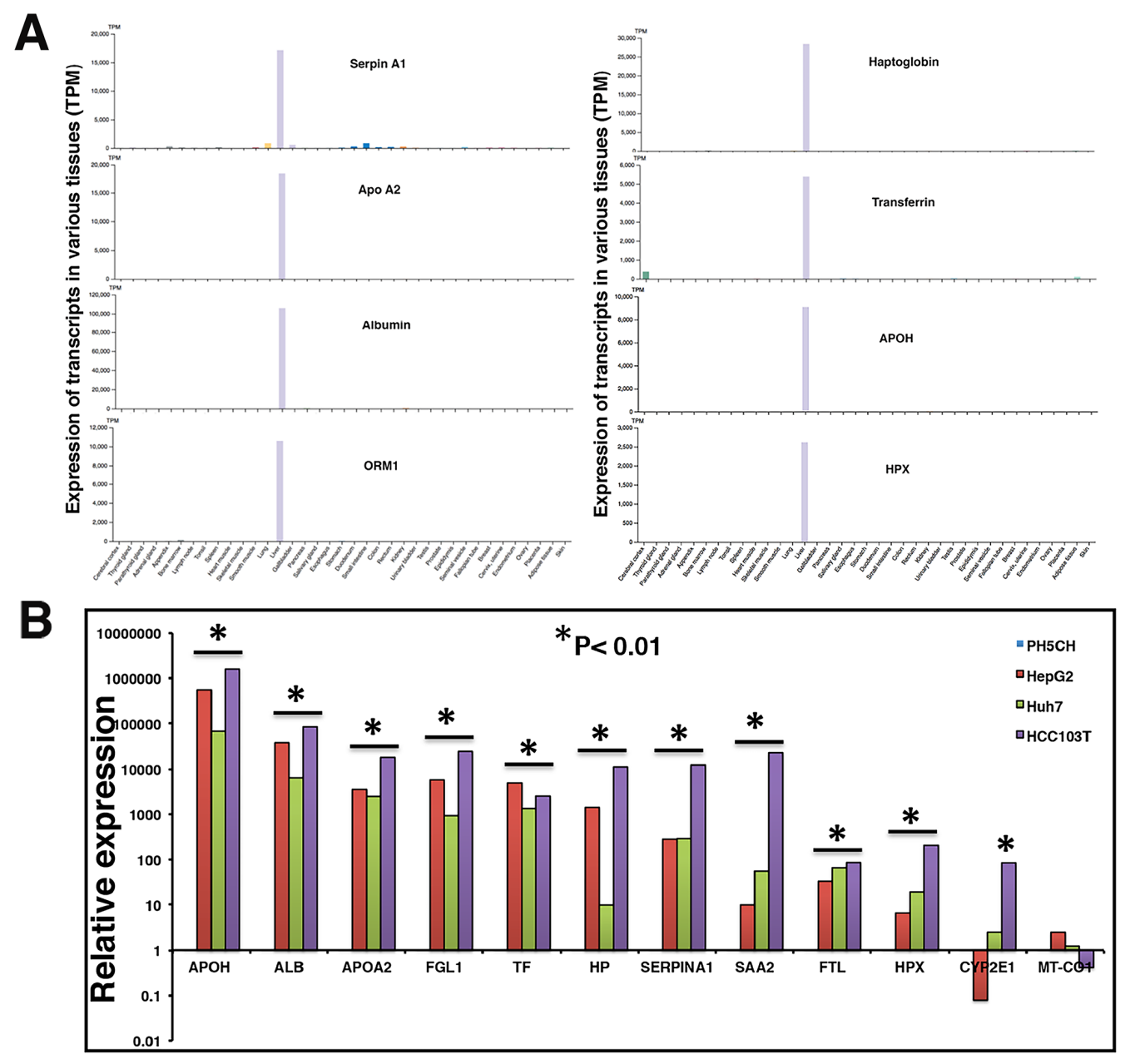

Figure 4: Liver specificity of circulating transcripts investigated in Human Protein Atlas (HPA) dataset, HCC tumor, and cell lines. (A) Expression profiles of transcripts were evaluated in HPA dataset (version 19.2, Ensemble version 92.38) representing expression levels in 37 human tissues based on RNAseq. Y-axis reflects expression in transcripts per million (TPM). (B) Relative expression of some liver specific transcripts was investigated in a tumor tissue (HCC103T) and cancer cell lines HepG2 and Huh7. Expression profiles were normalized with GAPDH expression and expression in non-malignant PH5CH liver cells. Each RT-qPCR reaction was carried out at least in triplicate and data are represented as mean values. Significant upregulation in comparison to control PH5CH cells is reflected by asterisk sign $(p<0.01)$. 
(Figure 7B lower panel). Detection of a set of liver derived circulating transcripts in HCC plasma samples was also demonstrated using nCounter Elements assay (Nanostring technology), which directly measures mRNA transcripts without the need for reverse transcription and PCR amplification (data not shown).

\section{Liver derived transcripts predominantly detected outside extracellular vesicles (EVs) in circulation}

Extracellular vesicles (EVs) consisting of exosomes and microvesicles (MVs) are small membrane-

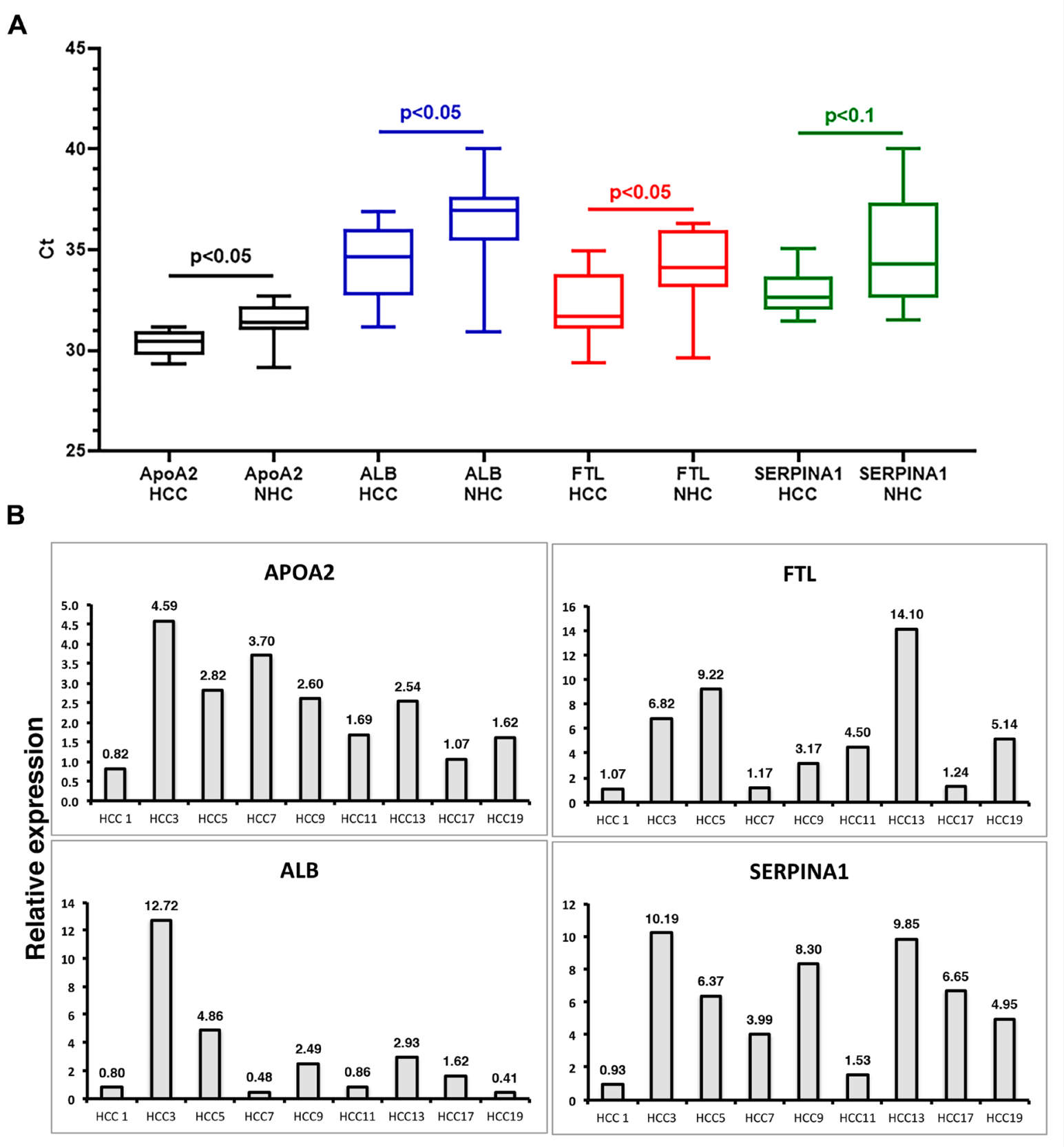

Figure 5: Validation of liver derived circulating transcripts by RT-qPCR in an independent dataset. (A) Relative expression of liver specific circulating transcripts in a cohort of $10 \mathrm{HCC}$ patients compared to 10 age/gender matched normal healthy control (NHC) samples was investigated by RT-qPCR. Average Ct values in HCC and NHC samples are plotted. Statistical significance was calculated by unpaired Student's $t$-test. (B) Relative expression calculated by $\Delta \Delta C t$ method. $\Delta C t$ values of HCC samples were calculated by subtracting spike-in ultramer $\mathrm{Ct}$ from $\mathrm{Ct}$ of target transcripts. $\mathrm{Ct}$ values of $10 \mathrm{NHC}$ samples were averaged and normalized with respective ultramer $\mathrm{Ct}$ values to get an average NHC $\Delta \mathrm{Ct}$. $\Delta \Delta \mathrm{Ct}$ of HCC samples was calculated by subtracting average NHC $\Delta \mathrm{Ct}$ from each HCC sample $\Delta \mathrm{Ct}$. Relative expression calculated by formula $2^{-\Delta \Delta \mathrm{Ct}}$ plotted as bar graphs. Each qPCR reaction was run at least in triplicate and data are represented as mean values. Sequence of oligos used can be found in Supplementary Materials and Methods. 
enclosed particles of endosomal and plasma membrane origin, respectively, that are released by cells into the extracellular environment. These membrane-bound vesicles represent an important mode of intercellular communication. miRNA and other "cargo" from intracellular compartments, expressed in the circulation, have been reported to be contained within EVs (reviewed in Couto et al. [34]). It has been suggested that circulating EVs can be used as noninvasive biomarkers for early detection, diagnosis, and treatment of cancer [35]. Our analysis on plasma, so far, used methods that did not distinguish between mRNA contained within or outside of EVs. It was therefore of interest to determine if the circulating transcripts are located within EVs or circulate as membrane-free molecules (EV-free).

To optimize the purification of EVs in plasma samples, we first evaluated $\mathrm{EV}$ isolation from liver cancer cell lines. Figure 8A shows the enrichment of unique EV markers CD9, CD63, CD81, and Alix by immunoblotting. $\mathrm{EV}$ isolation was then carried out with HCC and LC patient plasma samples and further characterization carried out by nanoparticle tracking analysis (NTA) and immunoblotting (Figure 8B, 8C; Supplementary Figure 4). NTA of these samples confirmed particle size ranges between 50 to 150 $\mu \mathrm{m}$, which are specifically characteristic of exosomes (Figure 8C). RNA was isolated from total plasma and two plasma sub-fractions, EV and EV-free, from the same patient (HCC101P) and followed by RNAseq analysis.
The results show that although transcripts such as $M T$ CO2, FTL, TMSB4X, HBA1, and other mitochondrial and ribosomal transcripts were uniformly present inside and outside circulating EVs, liver specific transcripts were predominantly abundant in the EV-free fraction. Bar graphs (Figure 8D) highlight the differential expression (TPM) of circulating transcripts. The results suggest that major tissue specific transcripts are predominantly present in plasma outside vesicles. Figure $8 \mathrm{E}$ shows a snapshot of read piles of four circulating transcripts including liver specific $A P O A 2$ and SERPINA1 in $\mathrm{EV} / \mathrm{EV}$-free fractions and total unfractionated plasma. Note that FTL and HBAI transcripts are represented in both fractions, while $A P O A 2$ and $A P O E$ are preferentially detected in EV-free plasma, highlighting the differential expression. It is tempting to speculate that these transcript fragments might exist as protein nucleic acid complexes that ensure protection from ubiquitous nucleases in the circulation.

\section{DISCUSSION}

Here we show that human plasma, among a diverse family of RNA transcripts, contains mRNA corresponding to more than 19,000 different coding genes. The differential sequencing depths and read pile densities within exons suggest that circulating mRNA transcripts likely exist as fragments. Investigation into the contents of circulating EVs implied that mRNA transcripts are located within and

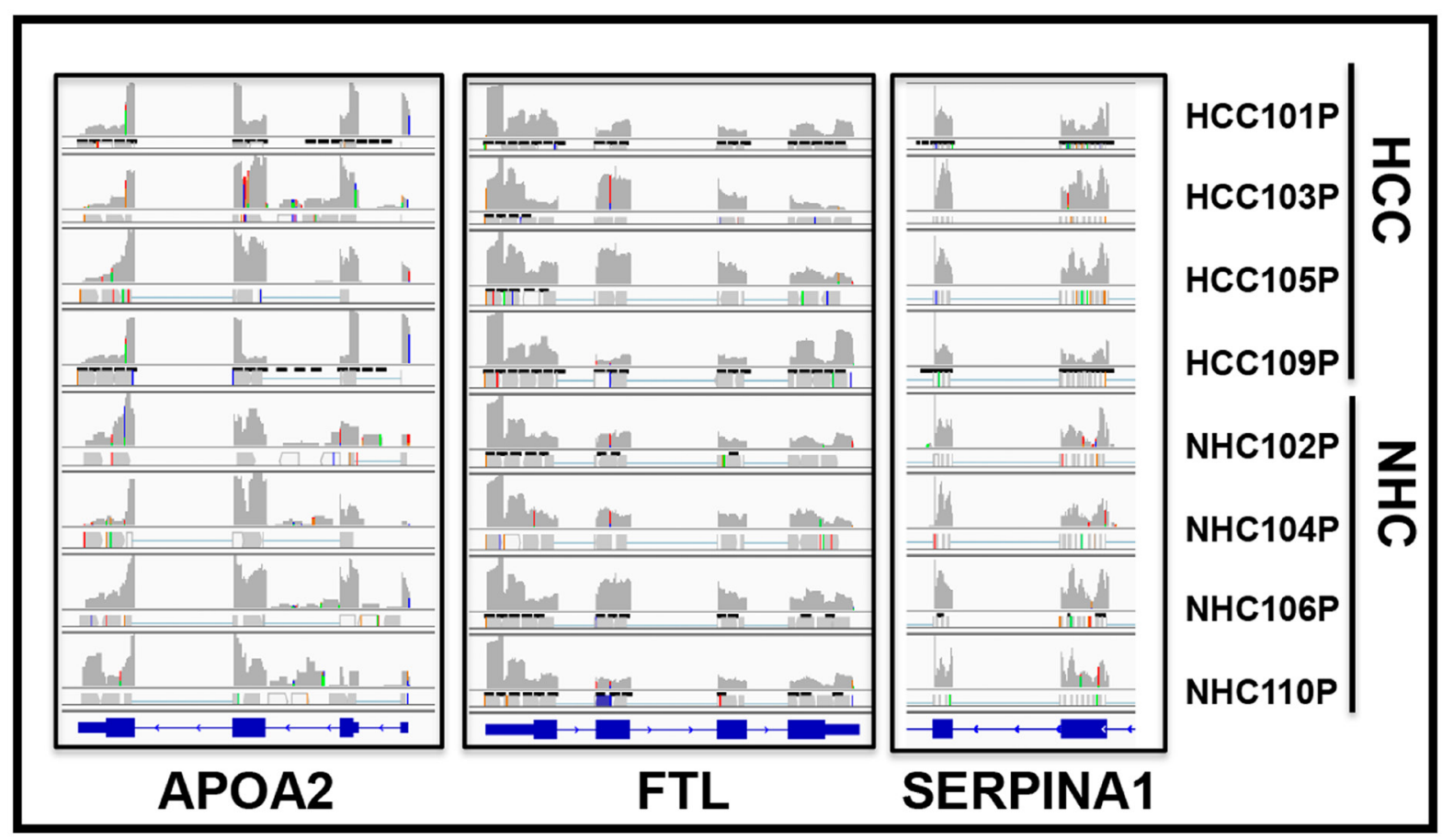

Figure 6: Circulating transcripts predominantly map to genomic exons. RNAseq read piles in plasma samples from $4 \mathrm{HCC}$ patients and their age and gender matched normal healthy controls (NHC) analyzed in a single flow cell experiment. Alignment to 3 genes in 8 samples is shown and suggests that circulating transcript sequences overwhelmingly align to exons and not introns. Histograms show relative distribution of detected mRNA reads. Specific regions within exons show higher sequencing depth than others and patterns are largely consistent across samples. RefSeq gene model diagrams shown at bottom of read piles. 
outside EVs. Many of these coding transcripts came from the liver and other solid organs, and liver derived transcripts were predominantly found outside circulating EVs. One unique observation is that the level of any circulating mRNA transcript was very similar from patient to patient, not varying by more than 8 -fold for $94 \%$ of the different gene transcripts, which suggests that the circulating human mRNA transcriptome is remarkably consistent.

We demonstrate the upregulation of cancer specific transcripts in the circulation of HCC patients compared to
LC patients. Consistent with our results, a growing body of evidence exists supporting the presence of circulating mRNA in various cancer patients $[11,12,36]$. Serum hTERT mRNA in HCC patients correlated with clinical variables such as tumor size, number, and degree of differentiation [14]. A multi-centered trial demonstrated the sensitivity/specificity of HCC diagnosis by $h T E R T$ mRNA as $90.2 \% / 85.4 \%$ and indicated that it was superior to AFP, AFP-L3, and DCP in the diagnosis of HCC [15]. Similar performance using serum hTERT mRNA was
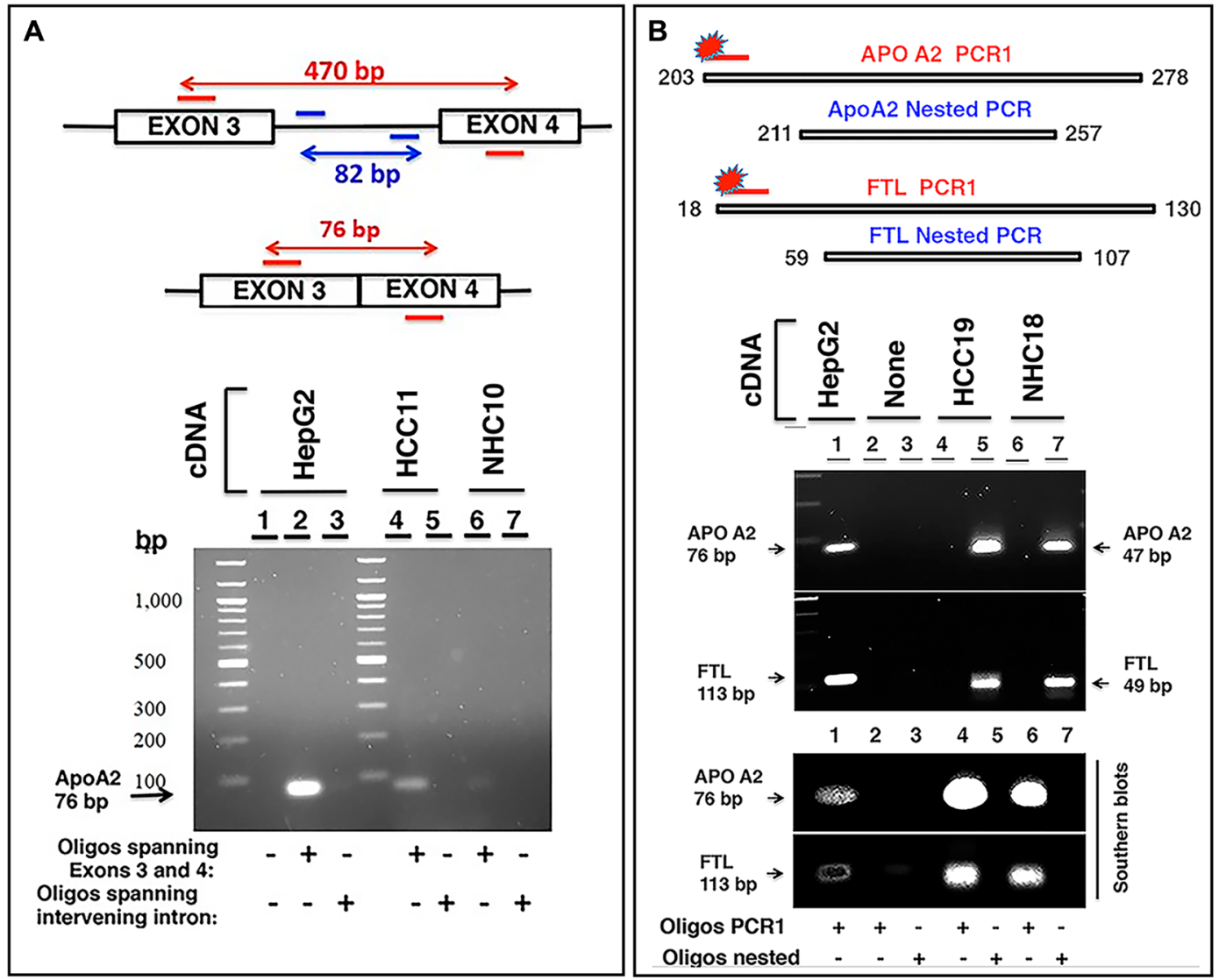

Figure 7: Characterization of circulating transcripts using semi-quantitative nested PCR and Southern blotting. (A) APOA2 gene consisting of 4 exons was studied in two clinical samples, HCC11 (cancer patient) and NHC10 (normal healthy control) using $100 \mathrm{ng}$ cDNA in each reaction. Two oligo sets were prepared: one set encompassing regions of exon 3 and exon 4 and the other set corresponding to the intervening intron (amplifying an $82 \mathrm{bp}$ fragment). A short product of $76 \mathrm{bp}$ was expected to be amplified by the former oligo set if no intron was present between the exons in the amplified fragment. Genomic DNA or even unspliced mRNA would yield a 470 bp product. Visualized gel demonstrates that the $76 \mathrm{bp} A P O A 2$ product corresponding to primers spanning exons 3 and 4 is detected and shows higher expression in HCC11 sample compared to NHC10, but intron specific primers do not yield any product. HepG2 cDNA was used as a positive control. (B) Two sets of primer pairs, corresponding to PCR1 extended amplicon and nested amplicon were used to amplify APOA2 and FTL transcripts in two samples, HCC19 and NHC18. PCR1 was carried out for 30 cycles using extended PCR1 oligos. PCR1 product was diluted 12.5-fold and subjected to nested PCR using nested oligos. Products were separated by electrophoresis on a $2 \%$ agarose gel. PCR1 products could not be detected, but the nested APOA2 (47 bp) and FTL (49 bp) products were clearly observed. HepG2 cDNA was used as a control. As expected, the inner nested oligo sets yielded smaller products (47 bp for $A P O A 2,49$ bp for FTL), while outer PCR1 sets of oligos yielded a larger product (76 bp for APOA2, $113 \mathrm{bp}$ for FTL). Gel resolved PCR1 and nested PCR products were transferred to a nylon membrane followed by hybridization with extended PCR 1 specific $5^{\prime}$-LICOR 800 tagged oligos. As expected, 5 '-LICOR 800 probes did not detect the nested products. The positive control in lane 1, using PCR1 extended primer set and HepG2 cellular cDNA as template, reflects the extended PCR1 products of these transcripts. Lanes 2 and 3 are no template negative controls with either extended PCR1 (lane 2) or nested (lane 3) oligos. Lanes 4 and 6 reflect the extended PCR1 products in two patients, while lanes 5 and 7 represent nested products that are not detected by Southern blot using 5'-LICOR 800 tagged oligos in the same samples. Sequences of oligos can be found in Supplementary Materials and Methods. 
demonstrated in breast cancer [17, 37]. Albumin mRNA has also been detected in the peripheral blood of advanced stage (TNM stages III and IV) HCC patients. While it has been reported that liver transplantation in HCC patients reduced albumin mRNA below detectable limit, recurrence of HCC led to detectable levels of circulating albumin mRNA. No circulating albumin mRNA was detected in healthy individuals or cirrhotic liver patients [38]. Higher levels of plasma albumin mRNA were also detected in LC and active hepatitis $\mathrm{B}$ patients with a diagnostic sensitivity of more than $85 \%$ and specificity for detection over $90 \%$ [39]. Together, these reports clearly highlight the potential of circulating RNA in the detection of HCC.
Although the numbers of $\mathrm{HCC} / \mathrm{LC}$ patients represented in our study are too small for conclusive statements to be made about the prevalence or correlation of specific transcripts with any clinical states, we observed striking trends. Plasma samples from HCC patients contained elevated amounts of specific mRNAs and these samples were "grouped together" by the unsupervised analysis of the RNAseq data. Since the genes and polypeptides for many of these mRNAs (such as ALB, DUSP, FAS, SDF2L1, STRA13, MGAT2) have been reported elsewhere in the literature to be associated with $\mathrm{HCC}[15,20,29,40]$, it is tempting to suggest that their presence as mRNA in the circulation is related to the

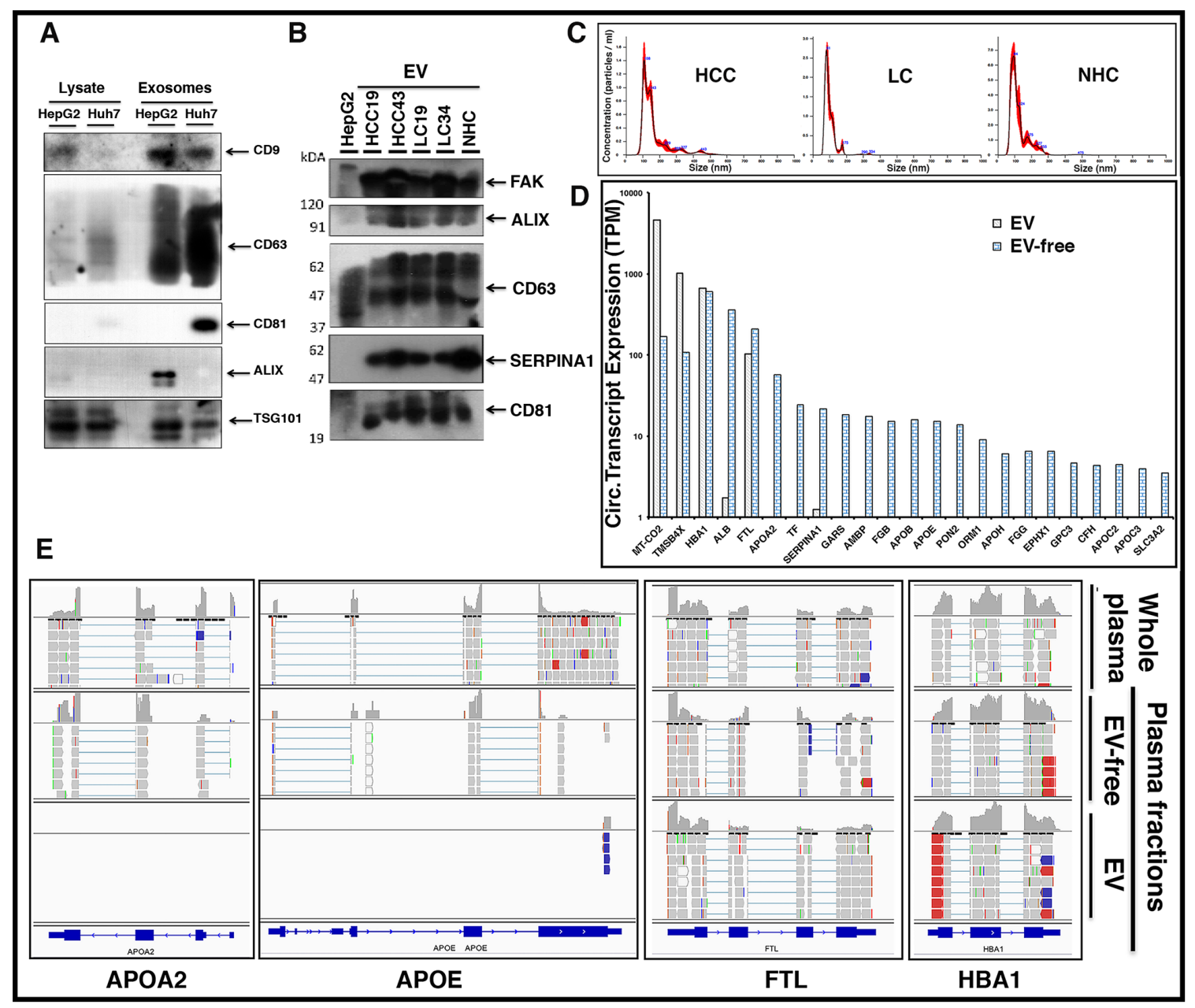

Figure 8: Circulating liver derived transcripts predominantly exist outside extracellular vesicles (EVs) in the plasma of HCC patients. (A) EVs were isolated from the culture media of HepG2 and Huh7 liver cancer cells and characterized by western blotting. Equal amounts of protein samples were loaded and the enrichment of tetraspanin receptors CD9, CD63, CD81, Alix, and TSG101 was tested as markers of EVs. (B) EVs from either HCC, LC, or normal healthy control (NHC) plasma samples were extracted using ExoQuick kit and further purified using ultracentrifugation. In addition to EV markers Alix, CD63, and CD81, liver specific marker SERPINA1 was investigated. FAK was used as a loading control. (C) Characterization of EVs from various plasma samples was done by NTA NanoSight NS300 system and NTA software analysis was used to obtain the size distribution and quantitation of particles. (D) Plasma sample from an $\mathrm{HCC}$ patient (HCC101P) was fractionated into EV fraction and remaining EV-free fraction. RNAseq analysis was carried out on RNA from total plasma and its two fractions. Comparative expression profiles (TPM) of circulating transcripts within and outside EVs for more than 20 liver derived transcripts are shown. (E) Read piles of some of the liver specific transcripts shown above in 6D for whole patient plasma, EVs, and EV-free fraction highlight the differential expression. FTL and HBA1 show almost equivalent levels of transcripts within and outside EVs, but $A P O A 2$ and $A P O E$ preferentially exist outside EVs. 
cancer diagnosis, despite the small numbers of samples used in this study.

Our data indicate that liver derived transcripts are predominantly present outside EVs. Endothelial cells in many blood vessels form an uninterrupted vasculature. However, as illustrated in Figure 9A, the discontinuous architecture and fusion of the luminal and abluminal plasma membrane at fenestrae, also called 'gaps,' of liver sinusoidal endothelial cells (LSECs) constitute a permeable barrier between blood cells on one side and hepatocytes and hepatic stellate cells on the other side, making them the most permeable endothelial cells of the mammalian body [41]. Further, the endothelium is thickened in HCC and loses its fenestrations while a discontinuous basement membrane is formed, resulting in vessels that are structurally and functionally abnormal [42]. It could be speculated that due to this known leaky vasculature in liver and other endocrine organs, detection of tissue specific circulating transcripts is not surprising.

The ability to detect mRNA in the blood could offer another non-invasive biomarker analyte and a liquid biopsy platform to detect and risk stratify disease, providing advantages to current non-invasive methods (Figure 9B). Primarily, it might be possible to detect mRNAs corresponding to non-secretory polypeptides in the blood or gene products that are present in extremely low abundance and cannot be detected with antibody assays. Also, detection of mutant genes and gene products is possible and, unlike mutated DNA that is usually single or limited copy number per cell, RNA is amplified. We have investigated the circulating human mRNA transcriptome and demonstrated dysregulation of certain liver and cancer specific mRNA transcripts in the circulation of HCC patients. However, more work is needed to determine biological significance and establish a biomarker value of mRNA signatures in HCC clinical management.

\section{MATERIALS AND METHODS}

\section{Human subjects}

Human plasma samples used in this study were from the Corporal Michael J. Crescenz VA Hospital,

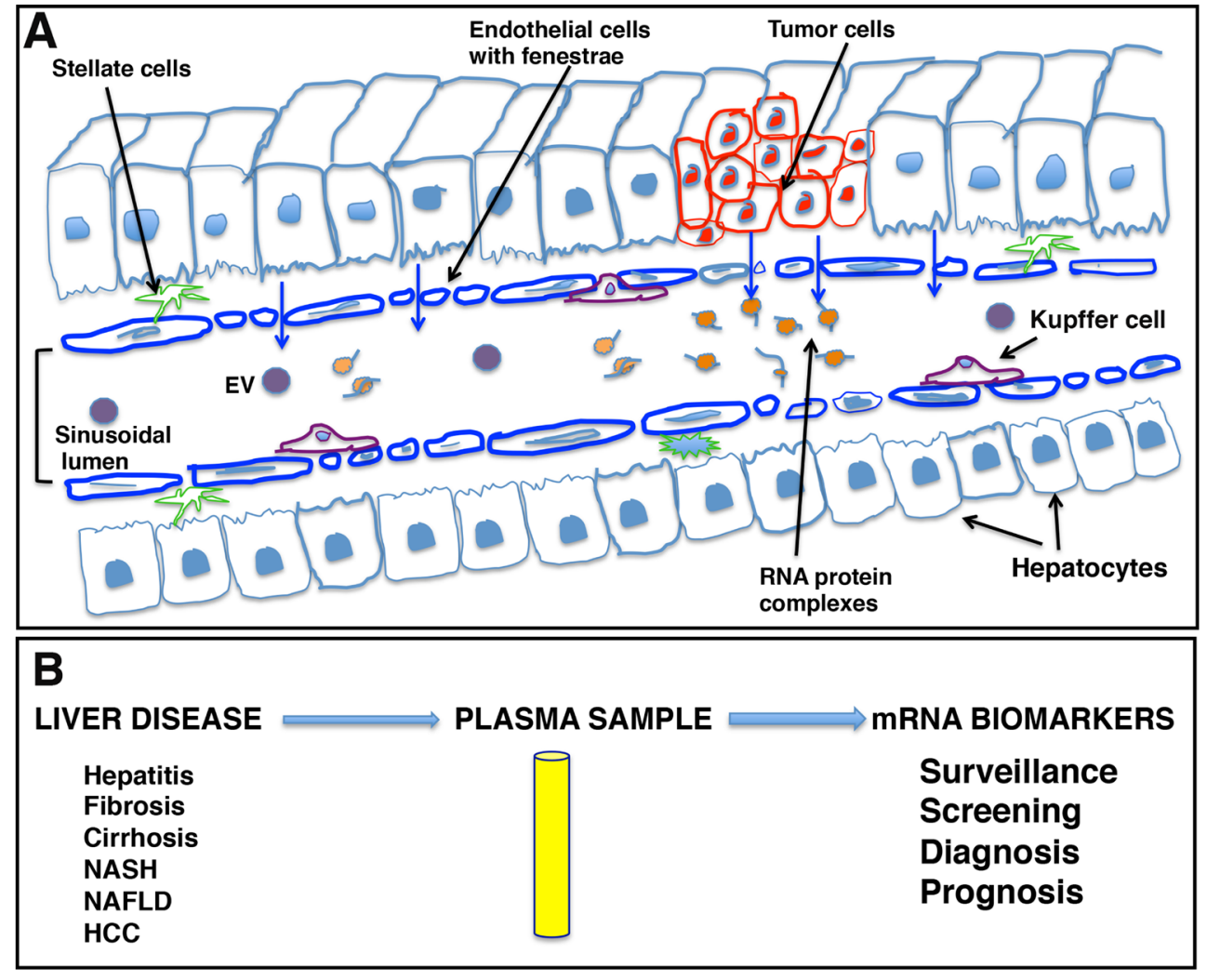

Figure 9: Schematic representation of liver sinusoids and loose architecture of liver endothelium. (A) Liver sinusoids. Sinusoids are highly modified leaky fenestrated capillaries with large lumens found in the liver, bone marrow, lymphoid tissue, and in some endocrine organs. The discontinuous architecture and fusion of the luminal and abluminal plasma membrane at fenestrae or gaps of liver sinusoidal endothelial cells (LSECs) result in leaky endothelium. This leaky vasculature may contribute to the transport of cellular cargo, extracellular vesicles (EVs), and large molecules like RNA-protein complexes from liver cells into blood. (B) mRNA signatures as potential liver disease biomarkers. The leaky endothelium provides an opportunity for development of a liquid biopsy platform for liver diseases, including hepatocellular carcinoma, where patient plasma can be tested for the presence of certain disease specific transcripts as biomarker analytes and can be effectively used in patient management. 
Philadelphia, PA (CMCVAMC); the University of Texas, Houston, TX; and a commercial supplier, BioChemed Services, Inc., Winchester, VA. RNAseq was carried out on plasma samples from CMCVAMC and BioChemed. Patient characteristics are summarized in Table 1 and explained in detail in Supporting Materials and Methods. RT-qPCR validation was performed on $\mathrm{HBsAg}$ positive $\mathrm{HCC}$ patients, ages $45-75$ years $(n=10)$, and $\mathrm{HBsAg} / \mathrm{HCC} / \mathrm{LC}$ negative age and gender matched individual controls $(n=$ 10) from University of Texas, Houston. Plasma samples and, in some cases, parallel tumor tissues from BioChemed were derived from both males and females (aged 57-74), with HCC histologically confirmed and staging provided. All samples used in our study were collected with informed consent in writing under IRB approved protocols.

\section{RNAseq experiment and analysis}

Total RNA from 1-2 ml plasma samples (spun at 2,000g for 5 minutes) was prepared using the Qiagen RNeasy Serum/Plasma Kit (Qiagen, Valencia, CA, USA) and quantified on a NanoDrop spectrophotometer. RNAseq analysis was carried out at Cancer Genomics Facility at Thomas Jefferson University (TJU), Philadelphia, PA, USA. RNA purity and integrity was assessed by Agilent 2100 BioAnalyzer. Libraries were prepared using the SMARTer ${ }^{\circledR}$ Stranded Total RNA-Seq Kit v2 (Takara Bio USA, Inc., Mountain View, CA, USA). Paired-end sequence reads were analyzed according to currently available best practices for whole-transcriptome analysis, which include alignment onto the current human reference genome assembly (GRCh38) using the STAR splice aware aligner. Transcript counts and abundances expressed in transcripts per million (TPM) were estimated based on GENCODE v28 gene annotations using the RSEM algorithm. Differential expression between groups was tested with the $\mathrm{R} /$ Bioconductor DESeq2 package. Tissue specific content was generated using the R/Bioconductor TissueEnrich package [43] (see Supporting Materials and Methods). Read piles of liver specific transcripts were analyzed using alignment .bam files corresponding to genome version GRCh38. The coverage density plots showed how many reads were aligned to a specific location, typically lining up with exon boundaries. Detailed information is provided in Supporting Materials and Methods. Tissue specificity of transcripts was also evaluated using Human Protein Atlas (HPA) dataset (version 19.2, Ensemble version 92.38), representing expression levels in 37 human tissues from 122 individuals based on RNAseq [44].

\section{RNA extraction from cell lines, tissues, extracellular vesicles (EVs), and EV-free plasma}

Total RNA was extracted from HCC cell lines HepG2 and Huh7 and immortalized normal liver $\mathrm{PH} 5 \mathrm{CH}$ cells using Qiagen miRNeasy Mini Kit (Qiagen, Valencia, CA, USA).
Total RNA was also extracted from two Grade-2 HCC tumor tissues (HCC103T, HCC105T, BioChemed) and a normal liver tissue using mirVana miRNA Isolation Kit (Ambion, Austin, TX, USA). All kits were used by following manufacturer guidelines. Tumor samples corresponding to two plasma samples (HCC103P, HCC105P, BioChemed) were investigated by RNAseq and one of them (HCC103T) was also studied by RT-qPCR. $100 \mathrm{mg}$ tissue treated with RNAlater-ICE solution (Invitrogen, Carlsbad, CA, USA) was homogenized in a glass homogenizer, worked-up following kit protocol, and RNA eluted in $100 \mu \mathrm{l}$ RNasefree water. Plasma ( $3 \mathrm{ml}$ ) from HCC101P (BioChemed) was spun at 2,000g for 15 minutes to remove cellular debris and supernatant was collected. Total RNA from extracellular vesicles (EVs) was extracted using the ExoMir Kit (BIOO Scientific Corp., Austin, TX, USA). RNA from the remaining EV-free flow-through plasma was extracted using the Qiagen RNeasy Serum/Plasma Kit (Qiagen, Valencia, CA, USA). RNA from plasma EVs, EV-free plasma, and liver tissues was sequenced at TJU as described above.

\section{RT-qPCR}

RNA samples from cell lines and tumor tissue (2.5 $\mu \mathrm{g})$ were subjected to DNase digestion before reverse transcription to cDNA. $50 \mathrm{ng}$ qPCR reactions were set in triplicate using LightCycler 480 SYBR Green I Master reaction mix and LightCycler 480 System (Roche Diagnostics, Indianapolis, IN, USA). $\triangle \mathrm{Ct}$ values were calculated by subtracting $\mathrm{Ct}$ values of $G A P D H$ in each sample from $\mathrm{Ct}$ values of target genes. $\triangle \mathrm{Ct}$ values of tumor and $\mathrm{HCC}$ cell lines were normalized with $\Delta \mathrm{Ct}$ values of liver $\mathrm{PH} 5 \mathrm{CH}$ cells to yield $\Delta \Delta \mathrm{Ct}$ values and relative expression was calculated using the formula $2^{-\Delta \Delta \mathrm{Ct}}$. RNA from clinical plasma samples (1 to $2 \mathrm{ml}$ ) was prepared using the Qiagen RNeasy Serum/Plasma Kit (Qiagen, Valencia, CA, USA). RNA was subjected to DNase digestion before reverse transcription to cDNA. Each cDNA sample was spiked with specific copy number of a 102 nt zebrafish-specific DNA ultramer (IDT, Coralville, IA) for use as internal control. PCR reactions for each sample $(n=20)$ with 25 ng cDNA were subjected to qPCR. Primers were designed corresponding to high sequencing depth regions identified from RNAseq (Supplementary Table 1). Relative expression of each transcript was calculated using the $\Delta \Delta \mathrm{Ct}$ method by normalizing with internal reference DNA ultramer and the average $\Delta \mathrm{Ct}$ value $(n=10)$ from age and gender matched NHC samples. Each PCR reaction was carried out in triplicate sets and relative expression determined.

\section{Semi-quantitative nested PCR and Southern blots}

Clinical plasma samples from HCC patient HCC11 and $\mathrm{NHC10}$ were investigated for liver derived $A P O A 2$ mRNA. Two sets of oligos were designed. One oligo set had forward/reverse primers specific for $A P O A 2$ exon 3/exon 4, 
respectively, and amplified a short product of $76 \mathrm{bp}$ when no intron was present in the transcript. The other set consisted of oligos specific for the intervening intron between exons 3 and 4 and amplified an 82 bp fragment. Semi-quantitative PCR reactions were carried out using either exon 3 and 4 specific oligos or oligos corresponding to the intervening intron. PCR was carried out for 30 cycles and products were resolved by electrophoresis on a $2 \%$ agarose gel. For further validation and characterization of circulating transcripts, nested PCR in clinical plasma samples was carried out (HCC patient HCC19 and NHC18) to study APOA2 and FTL transcripts. Two sets of oligos, corresponding to PCR1 extended amplicon and nested amplicon, were used to amplify APOA2 and FTL cDNA. PCR1 was carried out for 30 cycles using extended PCR1 oligos. PCR1 product was diluted 12.5-fold and subjected to additional 30 cycle nested PCR using nested oligos. Both PCR1 and nested PCR products were resolved by electrophoresis on a $2 \%$ agarose gel. Outer PCR1 oligo sets yield a larger product ( $76 \mathrm{bp}$ for $A P O A 2,113$ bp for $F T L)$, while inner nested oligo sets yield smaller products (47 bp for APOA2, $49 \mathrm{bp}$ for $F T L$ ). PCR1 and nested PCR products were transferred to an Amersham Hybond- $\mathrm{N}^{+}$membrane (GE Healthcare Life Sciences, Marlborough, MA, USA) followed by hybridization with extended PCR1 specific 5'-LICOR 800 tagged oligos (IDT, Coralville, IA, USA) for Southern blot based detection of PCR amplified transcripts. 5'-LICOR 800 probes incorporate in PCR1 products, but not in nested products.

\section{Isolation and characterization of EVs}

EVs were purified from HepG2 and Huh7 liver cancer cell lines as previously described $[45,46]$ with some modifications. Briefly, the culture supernatant was collected after 48 hours of starvation, pre-cleared of any cellular debris at $2,000 \mathrm{~g}$ for 20 minutes at $4^{\circ} \mathrm{C}$, and centrifuged again at $10,000 \mathrm{~g}$ for 30 minutes at $4^{\circ} \mathrm{C}$. The supernatant was ultracentrifuged at $100,000 \mathrm{~g}$ for 120 minutes at $4^{\circ} \mathrm{C}$. The EV pellet was washed in phosphate buffered saline (PBS) at $100,000 \mathrm{~g}$ for 120 minutes at $4^{\circ} \mathrm{C}$ and resuspended in PBS. Plasma samples (1 to $1.5 \mathrm{ml}$ ) from $\mathrm{HCC}$ patients and normal healthy controls (CMCVAMC) were spun at $2,000 \mathrm{~g}$ for 30 minutes to remove cellular debris before purification of EVs using ExoQuick kit (System Biosciences, Palo Alto, CA, USA). EVs were further purified by ultracentrifugation using PBS at 100,000g for 120 minutes at $4^{\circ} \mathrm{C}$. EV pellet was resuspended in PBS and quantified using NanoSight Tracking analysis (Malvern Instruments, Malvern, UK). Remaining EV suspension was lysed for further characterization. Additional details are in Supporting Materials and Methods.

\section{Immunoblotting (IB)}

EV isolation and characterization by IB was carried out as reported earlier $[47,48]$. Blocked membranes were probed with either rabbit monoclonal antibodies (mAbs) to TSG101 (ab125011) from Abcam (Cambridge, UK) and CD63 (55051) and FAK (13009) from Cell Signaling Technologies (Danvers, MA, USA) or mouse mAbs to human CD81 (ab23505) from Abcam, Alix (sc53540) and human CD9 (sc13118) from Santa Cruz Biotechnology, Inc. (Dallas, TX, USA), and human SERPINA1 (NBP252557) from Novus Biologicals (Littleton, CO, USA).

\section{Statistical analysis}

The reads for each mRNA obtained from the plasma of HCC, LC, and NHC patients were analyzed in separate generalized linear models with the assumption of negative binomial (NB) distribution using the DESeq2 software package. The $p$-values for each set of tests were adjusted for multiple testing using the False Discovery Rate (FDR) of $1 \%$. RT-qPCR data are shown as mean values and considered statistically significant at $p<0.05$. GraphPad Prism software (San Diego, CA, USA) was used for analysis. Western and Southern blot figures were assembled in Adobe Photoshop (Adobe Inc., San Jose, CA, USA).

\section{Abbreviations}

HCC: Hepatocellular carcinoma; LC: Liver cirrhosis; miRNA: microRNA; mRNA: messenger RNA; RNAseq: RNA sequencing; RT-qPCR: Reverse transcription-quantitative polymerase chain reaction; NHC: Normal healthy control; EVs: Extracellular vesicles; MVs: Microvesicles.

\section{Author contributions}

AS and TB conceptualized and designed the study. $\mathrm{AS}, \mathrm{AJ}$, and $\mathrm{BD}$ developed methodology, carried out experiments, and acquired data. AS, TB, BD, AE, and UV performed analysis and interpretation of data (e.g., statistical analysis, biostatistics, computational analysis). AS and TB wrote the manuscript. DK, LYH, and CD provided the clinical plasma samples and reviewed the manuscript. JK provided interpretive insights.

\section{ACKNOWLEDGMENTS}

We thank Dr. Chari Cohen (The Baruch S. Blumberg Institute) and Abhar Nissar for reviewing this manuscript. We are also thankful to Nancy Young and Judith Marchand for administrative assistance.

\section{Availability of data and materials}

Data generated or analyzed during this study are included in this published article and its supporting supplementary information files. Additional datasets are 
available from the corresponding author on reasonable request.

\section{CONFLICTS OF INTEREST}

The authors have declared that no conflicts of interest exists for this work. Timothy Block is on the Board of Directors of Hepion, an early phase company developing therapeutics for hepatitis B and other liver diseases. Cirna therapeutics is a startup company created by The Baruch S. Blumberg Institute developing early detection of cancer diagnostics that plans to license technology described in this work. None of the authors have any ownership in Cirna Therapeutics.

\section{FUNDING}

This study was supported by a Commonwealth University Research Enhancement Program grant with the Pennsylvania Department of Health (TB); the Department specifically disclaims responsibility for any analyses, interpretations, or conclusions. This work was also supported by NIH R01 CA166111 (DEK).

\section{REFERENCES}

1. Cortez MA, Calin GA. MicroRNA identification in plasma and serum: a new tool to diagnose and monitor diseases. Expert Opin Biol Ther. 2009; 9:703-711. https://doi. org/10.1517/14712590902932889. [PubMed]

2. Hunter MP, Ismail N, Zhang X, Aguda BD, Lee EJ, Yu L, Xiao T, Schafer J, Lee M-LT, Schmittgen TD, Nana-Sinkam SP, Jarjoura D, Marsh CB. Detection of microRNA expression in human peripheral blood microvesicles. PLoS One. 2008; 3:e3694. https://doi.org/10.1371/journal.pone.0003694. [PubMed]

3. Umu SU, Langseth H, Bucher-Johannessen C, Fromm B, Keller A, Meese E, Lauritzen M, Leithaug M, Lyle R, Rounge TB. A comprehensive profile of circulating RNAs in human serum. RNA Biol. 2018; 15:242-250. https://doi. org/10.1080/15476286.2017.1403003. [PubMed]

4. Akat KM, Lee YA, Hurley A, Morozov P, Max KEA, Brown M, Bogardus K, Sopeyin A, Hildner K, Diacovo TG, Neurath MF, Borggrefe M, Tuschl T. Detection of circulating extracellular mRNAs by modified small-RNAsequencing analysis. JCI Insight. 2019; 5:e127317. https:// doi.org/10.1172/jci.insight.127317. [PubMed]

5. García V, García JM, Peña C, Silva J, Domínguez G, Lorenzo Y, Diaz R, Espinosa P, de Sola JG, Cantos B, Bonilla F. Free circulating mRNA in plasma from breast cancer patients and clinical outcome. Cancer Lett. 2008; 263:312-320. https://doi.org/10.1016/i.canlet.2008.01.008. [PubMed]

6. Danielson KM, Rubio R, Abderazzaq F, Das S, Wang YE. High throughput sequencing of extracellular RNA from human plasma. PLoS One. 2017; 12:e0164644. https://doi. org/10.1371/journal.pone.0164644. [PubMed]

7. Kopreski MS, Benko FA, Kwak LW, Gocke CD. Detection of tumor messenger RNA in the serum of patients with malignant melanoma. Clin Cancer Res. 1999; 5:1961-5. [PubMed]

8. Kalinich M, Bhan I, Kwan TT, Miyamoto DT, Javaid S, LiCausi JA, Milner JD, Hong X, Goyal L, Sil S, Choz M, Ho U, Kapur R, et al. An RNA-based signature enables high specificity detection of circulating tumor cells in hepatocellular carcinoma. Proc Natl Acad Sci U S A. 2017; 114:1123-1128. https://doi.org/10.1073/pnas.1617032114. [PubMed]

9. Shen J, Wei J, Guan W, Wang H, Ding Y, Qian X, Yu L, Zou Z, Xie L, Costa C, Bivona T, Rosell R, Liu B. Plasma mRNA expression levels of BRCA1 and TS as potential predictive biomarkers for chemotherapy in gastric cancer. $\mathrm{J}$ Transl Med. 2014; 12:355. https://doi.org/10.1186/s12967014-0355-2. [PubMed]

10. Wong SCC, Lo SFE, Cheung MT, Ng KOE, Tse CW, Lai BSP, Lee KC, Lo YMD. Quantification of plasma $\beta$-catenin mRNA in colorectal cancer and adenoma patients. Clin Cancer Res. 2004; 10:1613-1617. https://doi. org/10.1158/1078-0432.CCR-1168-3. [PubMed]

11. Chen XQ, Bonnefoi H, Pelte MF, Lyautey J, Lederrey C, Movarekhi S, Schaeffer P, Mulcahy HE, Meyer P, Stroun M, Anker P. Telomerase RNA as a detection marker in the serum of breast cancer patients. Clin Cancer Res. 2000; 6:3823-3826. [ubMed]

12. Dasí F, Martínez-Rodes P, March JA, Santamaría J, Martínez-Javaloyas JM, Gil M, Aliño SF. Real-time quantification of human telomerase reverse transcriptase mRNA in the plasma of patients with prostate cancer. Ann N Y Acad Sci. 2006; 1075:204-210. https://doi.org/10.1196/ annals.1368.028. [PubMed]

13. Enache LS, Enache EL, Ramière C, Diaz O, Bancu L, Sin A, André P. Circulating RNA molecules as biomarkers in liver disease. Int J Mol Sci. 2014; 15:17644-17666. https:// doi.org/10.3390/ijms151017644. [PubMed]

14. Miura N, Maeda Y, Kanbe T, Yazama H, Takeda Y, Sato R, Tsukamoto T, Sato E, Marumoto A, Harada T, Sano A, Kishimoto Y, Hirooka Y, et al. Serum human telomerase reverse transcriptase messenger RNA as a novel tumor marker for hepatocellular carcinoma. Clin Cancer Res. 2005; 11:3205-3209. https://doi.org/10.1158/1078-0432. CCR-04-1487. [PubMed]

15. Miura N, Osaki Y, Nagashima M, Kohno M, Yorozu K, Shomori K, Kanbe T, Oyama K, Kishimoto Y, Maruyama S, Noma E, Horie Y, Kudo M, et al. A novel biomarker TERTmRNA is applicable for early detection of hepatoma. BMC Gastroenterol. 2010; 10:46. https://doi. org/10.1186/1471-230X-10-46. [PubMed]

16. Terrin L, Rampazzo E, Pucciarelli S, Agostini M, Bertorelle R, Esposito G, DelBianco P, Nitti D, De Rossi A. Relationship between tumor and plasma levels of hTERT 
mRNA in patients with colorectal cancer: implications for monitoring of neoplastic disease. Clin Cancer Res. 2008; 14:7444-7451. https://doi.org/10.1158/1078-0432.CCR-080478. [PubMed]

17. Fu X, Shen C, Wang H, Chen F, Li G, Wen Z. Joint quantitative measurement of hTERT mRNA in both peripheral blood and circulating tumor cells of patients with nasopharyngeal carcinoma and its clinical significance. BMC Cancer. 2017; 17:479. https://doi.org/10.1186/ s12885-017-3471-6. [PubMed]

18. Muller C, Petermann D, Pfeffel F, Oesterreicher C, Fugger R. Lack of specificity of albumin-mRNA-positive cells as a marker of circulating hepatoma cells. Hepatology. 1997; 25:896-899. https://doi.org/10.1002/hep.510250418. [PubMed]

19. Cheung ST, Fan ST, Lee YT, Chow JP, Ng IO, Fong DY, Lo CM. Albumin mRNA in plasma predicts posttransplant recurrence of patients with hepatocellular carcinoma. Transplantation. 2008; 85:81-87. https://doi. org/10.1097/01.tp.0000298003.88530.11. [PubMed]

20. Bermudez O, Pagès G, Gimond C. The dual-specificity MAP kinase phosphatases: critical roles in development and cancer. Am J Physiol Cell Physiol. 2010; 299:C189-C202. https://doi.org/10.1152/ajpcell.00347.2009. [PubMed]

21. Wang D, Han S, Peng R, Jiao C, Wang X, Han Z, Li X. DUSP28 contributes to human hepatocellular carcinoma via regulation of the p38 MAPK signaling. Int J Oncol. 2014; 45:2596-2604. https://doi.org/10.3892/ijo.2014.2653. [PubMed]

22. Koizume S, Jin MS, Miyagi E, Hirahara F, Nakamura Y, Piao JH, Asai A, Yoshida A, Tsuchiya E, Ruf W, Miyagi Y. Activation of cancer cell migration and invasion by ectopic synthesis of coagulation factor VII. Cancer Res. 2006; 66:9453-9460. https://doi.org/10.1158/0008-5472.CAN06-1803. [PubMed]

23. Suzuki A, Hayashida M, Kawano H, Sugimoto K, Nakano T, Shiraki K. Hepatocyte growth factor promotes cell survival from Fas-mediated cell death in hepatocellular carcinoma cells via Akt activation and Fas-death-inducing signaling complex suppression. Hepatology. 2000; 32:796802. https://doi.org/10.1053/jhep.2000.17738. [PubMed]

24. Ng CC, Yew PY, Puah SM, Krishnan G, Yap LF, Teo SH, Lim PVH, Govindaraju S, Ratnavelu K, Sam CK, Takahashi A, Kubo M, Kamatani N, et al. A genome-wide association study identifies ITGA9 conferring risk of nasopharyngeal carcinoma. J Hum Genet. 2009; 54:392-397. https://doi. org/10.1038/jhg.2009.49. [PubMed]

25. Zhang YL, Xing X, Cai LB, Zhu L, Yang XM, Wang YH, Yang Q, Nie HZ, Zhang ZG, Li J, Zhang XL. Integrin $\alpha 9$ suppresses hepatocellular carcinoma metastasis by Rho GTPase signaling. J Immunol Res. 2018; 2018:4602570. https://doi.org/10.1155/2018/4602570. [PubMed]

26. Porta-Pardo E, Godzik A. e-Driver: a novel method to identify protein regions driving cancer. Bioinformatics. 2014; 30:31093114. https://doi.org/10.1093/bioinformatics/btu499. [PubMed]
27. Zhang L, Qin D, Hao C, Shu X, Pei D. SNX16 negatively regulates the migration and tumorigenesis of MCF-7 cells. Cell Regen (Lond). 2013; 2:3. https://doi.org/10.1186/2045-9769-2-3. [PubMed]

28. Willis S, Villalobos VM, Gevaert O, Abramovitz M, Williams C, Sikic BI, Leyland-Jones B. Single gene prognostic biomarkers in ovarian cancer: a meta-analysis. PLoS One. 2016; 11:e0149183. https://doi.org/10.1371/ journal.pone.0149183. [PubMed]

29. Sasako T, Ohsugi M, Kubota N, Itoh S, Okazaki Y, Terai A, Kubota T, Yamashita S, Nakatsukasa K, Kamura T, Iwayama K, Tokuyama K, Kiyonari H, et al. Hepatic Sdf211 controls feeding-induced ER stress and regulates metabolism. Nat Commun. 2019; 10:947. https://doi. org/10.1038/s41467-019-08591-6. [PubMed]

30. Tiwari A, Schuiki I, Zhang L, Allister EM, Wheeler MB, Volchuk A. SDF2L1 interacts with the ER-associated degradation machinery and retards the degradation of mutant proinsulin in pancreatic $\beta$-cells. J Cell Sci. 2013; 126:1962-1968. https://doi.org/10.1242/jcs.117374. [PubMed]

31. Shi XH, Zheng Y, Sun Q, Cui J, Liu QH, Qü F, Wang YS. DEC1 nuclear expression: a marker of differentiation grade in hepatocellular carcinoma. World J Gastroenterol. 2011; 17:2037-2043. https://doi.org/10.3748/wjg.v17.i15.2037. [PubMed]

32. Agarwal E, Altman BJ, Seo JH, Ghosh JC, Kossenkov AV, Tang HY, Krishn SR, Languino LR, Gabrilovich DI, Speicher DW, Dang CV, Altieri DC. Myc-mediated transcriptional regulation of the mitochondrial chaperone TRAP1 controls primary and metastatic tumor growth. J Biol Chem. 2019; 294:10407-10414. https://doi. org/10.1074/jbc.AC119.008656. [PubMed]

33. Divella R, Mazzocca A, Gadaleta C, Simone G, Paradiso A, Quaranta M, Daniele A. Influence of plasminogen activator inhibitor-1 (SERPINE1) 4G/5G polymorphism on circulating SERPINE-1 antigen expression in HCC associated with viral infection. Cancer Genomics Proteomics. 2012; 9:193-198. [PubMed]

34. Couto N, Caja S, Maia J, Strano Moraes MC, CostaSilva B. Exosomes as emerging players in cancer biology. Biochimie. 2018; 155:2-10. https://doi.org/10.1016/j. biochi.2018.03.006. [PubMed]

35. Kalluri R. The biology and function of exosomes in cancer. J Clin Invest. 2016; 126:1208-1215. https://doi. org/10.1172/JCI81135. [ [PubMed]

36. Silva JM, Rodriguez R, Garcia JM, Muñoz C, Silva J, Dominguez G, Provencio M, España P, Bonilla F. Detection of epithelial tumour RNA in the plasma of colon cancer patients is associated with advanced stages and circulating tumour cells. Gut. 2002; 50:530-534. https:// doi.org/10.1136/gut.50.4.530. [PubMed]

37. Porika M, Tippani R, Bollam SR, Panuganti SD, Thamidala C, Abbagani S. Serum human telomerase reverse transcriptase: a novel biomarker for breast cancer diagnosis. 
Int J Clin Oncol. 2011; 16:617-622. https://doi.org/10.1007/ s10147-011-0230-6. [PubMed]

38. Kar S, Carr BI. Detection of liver cells in peripheral blood of patients with advanced-stage hepatocellular carcinoma. Hepatology. 1995; 21:403-407. [PubMed]

39. Chan RWY, Wong J, Chan HLY, Mok TSK, Lo WYW, Lee V, To KF, Lai PBS, Rainer TH, Lo YMD, Chiu RWK. Aberrant concentrations of liver-derived plasma albumin mRNA in liver pathologies. Clin Chem. 2010; 56:82-89. https://doi.org/10.1373/clinchem.2009.133355. [PubMed]

40. Cancer Genome Atlas Research Network. Comprehensive and integrative genomic characterization of hepatocellular carcinoma. Cell. 2017; 169:1327-41.e23. https://doi. org/10.1016/j.cell.2017.05.046. [PubMed]

41. Poisson J, Lemoinne S, Boulanger C, Durand F, Moreau R, Valla D, Rautou PE. Liver sinusoidal endothelial cells: physiology and role in liver diseases. J Hepatol. 2017; 66:212-227. https://doi.org/10.1016/j.jhep.2016.07.009. [PubMed]

42. Liu K, Zhang X, Xu W, Chen J, Yu J, Gamble JR, McCaughan GW. Targeting the vasculature in hepatocellular carcinoma treatment: starving versus normalizing blood supply. Clin Transl Gastroenterol. 2017; 8:e98. https://doi. org/10.1038/ctg.2017.28. [PubMed]

43. Jain A, Tuteja G. TissueEnrich: tissue-specific gene enrichment analysis. Bioinformatics. 2018; 35:1966-1967. https://doi.org/10.1093/bioinformatics/bty890. [PubMed]

44. Butler LM, Hallström BM, Fagerberg L, Pontén F, Uhlén M, Renné T, Odeberg J. Analysis of body-wide unfractionated tissue data to identify a core human endothelial transcriptome. Cell Syst. 2016; 3:287-301.e3. https://doi.org/10.1016/i.cels.2016.08.001. [PubMed]
45. Théry C, Amigorena S, Raposo G, Clayton A. Isolation and characterization of exosomes from cell culture supernatants and biological fluids. Current Protocols in Cell Biology. 2006; 30:3.22.1-29. https://doi.org/10.1002/0471143030. cb0322s30. [PubMed]

46. Fedele C, Singh A, Zerlanko BJ, Iozzo RV, Languino LR. The $\alpha v \beta 6$ integrin is transferred intercellularly via exosomes. J Biol Chem. 2015; 290:4545-4551. https://doi. org/10.1074/jbc.C114.617662. [PubMed]

47. Krishn SR, Singh A, Bowler N, Duffy AN, Friedman A, Fedele C, Kurtoglu S, Tripathi SK, Wang K, Hawkins A, Sayeed A, Goswami CP, Thakur ML, et al. Prostate cancer sheds the $\alpha \mathrm{v} \beta 3$ integrin in vivo through exosomes. Matrix Biol. 2019; 77:41-57. https://doi.org/10.1016/j. matbio.2018.08.004. [PubMed]

48. DeRita RM, Sayeed A, Garcia V, Krishn SR, Shields CD, Sarker S, Friedman A, McCue P, Molugu SK, Rodeck U, Dicker AP, Languino LR. Tumor-derived extracellular vesicles require $\beta 1$ integrins to promote anchorageindependent growth. iScience. 2019; 14:199-209. https:// doi.org/10.1016/j.isci.2019.03.022. [PubMed]

49. Uhlén M, Fagerberg L, Hallström BM, Lindskog C, Oksvold P, Mardinoglu A, Sivertsson Å, Kampf C, Sjöstedt E, Asplund A, Olsson I, Edlund K, Lundberg E, et al. Tissue-based map of the human proteome. Science. 2015; 347:1260419. https://doi.org/10.1126/science.1260419. [PubMed] 